\title{
Effects of Carbon Nanotube Ratio on Mechanical and Morphological Properties of A356-Carbon Nanotube Composites
}

\author{
H. EvLEN ${ }^{a, *}$ AND E. AKÇAER ${ }^{b}$ \\ ${ }^{a}$ Karabuk University, Department of Industrial Design Engineering, 78100 Karabuk, Turkey \\ ${ }^{b}$ Karabuk University, Graduate School of Natural and Applied Sciences, 78100 Karabuk, Turkey \\ In this study, CNT-A356 composites were obtained by reinforcing an aluminium alloy A356 matrix with 4 \\ different ratios $(0.5,1,1.5$ and $2 \%)$ of carbon nanotubes, and hardness, wear and microstructure properties of \\ these composites were investigated. Powder metallurgy method was used for producing composites. A356 powders \\ and CNTs were mixed via ball milling for $1 \mathrm{~h}$, and cold pressed in powder pressing mold. After that, mold was \\ taken into a functional furnace, and hot pressing operation was carried out. Pressed bulk was sintered in a vacuum \\ atmosphere $\left(10^{-6} \mathrm{mbar}\right)$ at $550^{\circ} \mathrm{C}$ for $1 \mathrm{~h}$. Hardness measurements, wear tests, and microstructure analyses of \\ produced samples were performed. As a result of experimental studies, CNTs were observed to be located as \\ agglomeration among matrix grains, and a more hollow structure was formed by increasing CNT ratio. Moreover, \\ weight loss increased as hardness values decreased when CNT ratio exceeded $1 \%$. The highest hardness value was \\ measured in composite with $1 \%$ CNT.
}

DOI: 10.12693/APhysPolA.135.668

PACS/topics: nanotube, CNT, A356, composite, powder metallurgy

\section{Introduction}

In recent years, metal matrix composites (MMC) are often preferred in the space industry, automotive industry, and medical field, where especially high strength, rigidity, high wear and corrosion resistance, superior mechanical and morphological properties are expected $[1,2]$. Since discovery of CNTs and recognition of their unique mechanical, thermal, and electrical properties, many researchers have attempted to produce CNT reinforced metal-matrix composites that exhibit one or more of these properties [3-8]. $\mathrm{Al}, \mathrm{Ti}, \mathrm{Mg}, \mathrm{Si}$, and $\mathrm{Cu}$ are used intensively as matrix in CNT reinforced composites. The powder metallurgy (PM) method is commonly used in production of Al-CNT composites. Some properties of this method like facilitating distribution of CNTs and promising about overcoming nanotube accumulation, which is one of main problem of developing CNT reinforced MMC, make it important. In recent research, it is seen that CNT reinforced A356 composites are produced via various methods $[3,4]$.

In this study, PM method was used to produce A356 alloy reinforced with different ratios of MWCNT, and cold and hot pressings were carried out together in this method. Hardness measurements, scanning electron microscopy (SEM) analyses and wear tests under 10N load were performed. Results were compared and discussed by using graphs and SEM analyses.

\footnotetext{
*corresponding author; e-mail: hakgul@karabuk.edu.tr
}

\section{Materials and equipments}

90\% pure MWCNT (by Nanografi) and atomized A356 (6.5\% Si, $0.4 \% \mathrm{Mg}, 0.15 \% \mathrm{Fe}, 0.2 \% \mathrm{Ti}, 0.03 \% \mathrm{Mn}$, $0.03 \% \mathrm{Cu}, 0.05 \% \mathrm{Zn}, 92.61 \% \mathrm{Al}$ ) (by Gazi University) were mixed in a planetary type ball mill with a steel milling bowl at a rate of 10:1 (ball:powder) and stirred at $400 \mathrm{rpm}$ for $1 \mathrm{~h}$. Stearic acid (1\%) and ethyl alcohol were used as process control agent (PCA). A356-CNT powder mixtures prepared by adding CNT at different ratios $(0,0.5,1,1.5$, and $2 \%)$ were cold pressed in a powder compression mold at a unidirectional pressure of $694 \mathrm{MPa}$. After that, mold was taken into a functional furnace for hot pressing (HP). HP was carried out by applying a pressure of $2.8 \mathrm{MPa}$ to mold at $200^{\circ} \mathrm{C}$ for $1 \mathrm{~h}$. Then, bulk was sintered in a vacuum atmosphere purged by supplying argon gas for $5 \mathrm{~min}$, at $500{ }^{\circ} \mathrm{C}$ for $1 \mathrm{~h}$. Sintered samples were sanded with 180 , 240, 600, 1200 grits of sand papers, respectively, and were polished by using diamond paste, and then were cauterized with Keller's reactivity consisting of purified water $(23.75 \mathrm{ml}), \mathrm{HF}(0.125 \mathrm{ml}), \mathrm{HCl}(0.375 \mathrm{ml})$, and $\mathrm{HNO}_{3}(0.665 \mathrm{ml})$. Microstructures of samples were examined by SEM analysis. Hardness measurements were made by using $4.9 \mathrm{~N}$ load and $10 \mathrm{~s}$ load application time and then taking 5 measurement values from each sample surface. Wear tests were carried out on a pin-on-disc type abrasion device under a $10 \mathrm{~N}$ load, at a shear velocity of $1 \mathrm{~m} / \mathrm{s}$ and at 4 different sliding distances (300-1200 m). 


\section{Results and discussion}

\subsection{Microstructure examinations}

SEM and mapping analysis of aluminium matrix composites (AMCs), produced by adding in $0.5 \%, 1 \%, 1.5 \%$, and $2 \%$ of MWCNTs to A356, produced with PM procedure, can be seen in Fig. 1. It is seen from the SEM and mapping analyses in Fig. 1 that when $5 \%$ CNT is added to the matrix material, CNT particles exhibit a uniform distribution within the matrix while there is condensation in the grain boundaries (Fig. 1a). However, it can be seen that when the ratio of CNT is up to $2 \%$, a homogeneous mixture cannot be obtained, and that the CNT content is agglomerated between grain boundaries of the $\mathrm{Al}$ matrix (Fig. $1 \mathrm{~b}$ and $\mathrm{c}$ ). It has been described that this heterogeneous distribution of CNTs is due to size difference between A356 powders and CNTs.

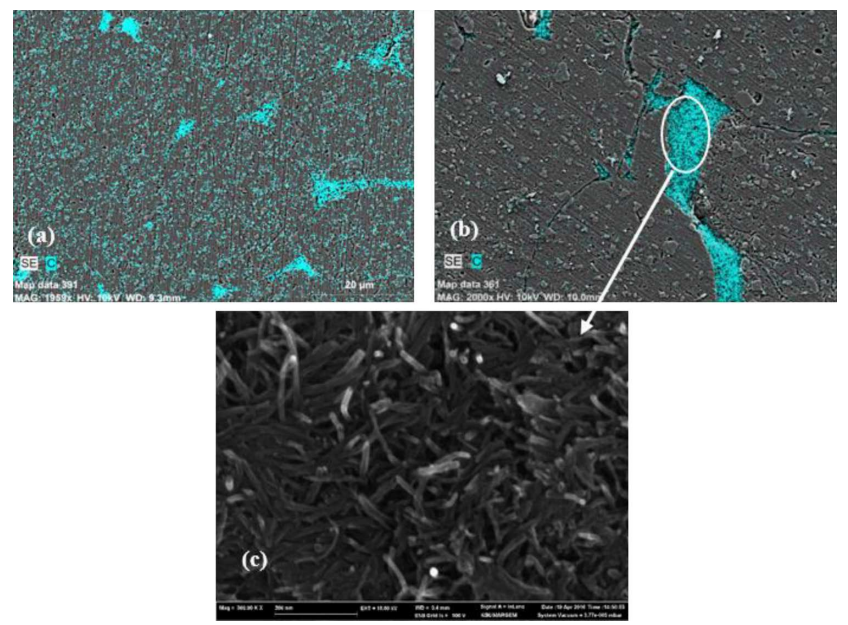

Fig. 1. CNT distribution in (a) A356-0.5\% CNT, (b) A356-2\% CNT composites, (c) CNT agglomerations viewed at grain boundaries in $2 \% \mathrm{CNT}$ composite.

In their study, Ylldırım et al. [5] produced CNT reinforcement to the A7075 matrix material in different rates and realized the sample production by PM method. They emphasized that, as the ratio of the reinforcing element increases, a heterogeneous mixture is formed, and the CNT particles are deposited in the grain boundaries of the matrix material. They attributed this situation to the dissimilarity on the particle sizes of the matrix material $(\mu \mathrm{m})$ and reinforcement element (nanosized).

\subsection{Hardness test results}

Figure 2 shows the results of hardness measurement. As a result of hardness measurements, hardness value of 0\% CNT-A356 sample was measured as $27.28 \mathrm{HV}$. Hardness values of composites containing 1 and 1.5\% CNT were found to be very close to each other. These values are 37.85 and $37.46 \mathrm{HV}$, respectively. It was found that hardness of $2 \%$ CNT-A356 composite was lower by $13 \%$ compared to $1.5 \%$ CNT-A356 and higher by $19 \%$ compared to 0\% CNT-A356 (32.53 HV).

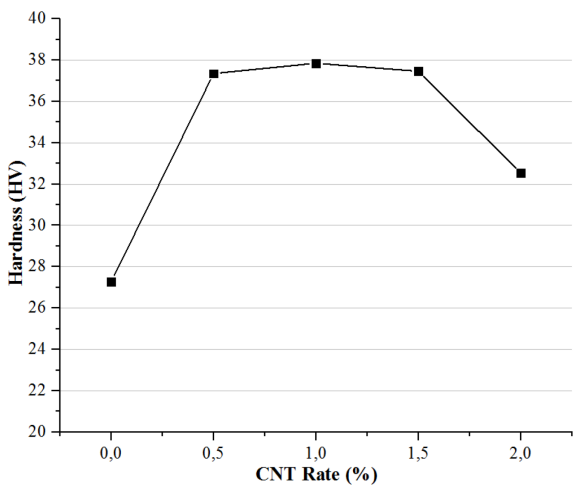

Fig. 2. Hardness variation of aluminum composites with CNT addition in different amounts.

In general, it was observed that the hardness values of the composite increased when the CNT ratio was $0.5 \%$ and $1 \%$. However, when the ratio of CNT continued to increase, the hardness values decreased. This is due to the inability of the $\mathrm{Al}$ matrix material to be mixed homogeneously with the CNT reinforcing element. CNT particles at low CNT ratios were placed in the gaps in the grain boundaries of the $\mathrm{Al}$ matrix and this increased the hardness value of the composite. As the CNT supplementation rate increased, no homogeneous mixture was obtained. Hence, the CNT particles formed the agglomeration of the grain boundaries of the matrix material. These agglomerations increased the gap in the grain boundaries and thus reduced the hardness of the composite. This local agglomerations around grain boundaries has been reported in previous microstructure examinations. Deng et al. [6] also encountered a similar situation in their study and stressed that this is due to the fact that the matrix material and the reinforcing element cannot be mixed homogeneously.

\subsection{Wear tests results}

Results of wear tests show that average weight loss and wear rate increases as CNT content increases, as shown in Fig. 3a. The highest weight loss occurred in 2\% CNTA356 composite $(115.8 \mathrm{mg})$ and the least weight loss occurred in CNT-free A356 material (22.9 mg). Also Fig. 3a shows that wear rate values support the weight loss results according to amount of CNT. In addition, hardness value decreased, weight loss and wear rate increased while CNT ratio was increasing from $1.5 \%$ to $2 \%$ (Fig. 2 and Fig. 3a). In previous studies, this case was explained that decrease of wear rate and wear loss values and increase of hardness values resulted from increase in ratio of reinforcement phase $[5,7,8]$. Although friction coefficient values are very close to each other, friction coefficient, weight loss, and wear rate values do not exactly support each other. It is clear that the relationship between the friction coefficient-weight loss-wear rate of conventional particle-reinforced AMCs does not support this situation. It is thought that this case is related to prefer reinforcing phase in conventional particle-reinforced composites and nano AMC production method. 
In nano AMCs, the reduction of some mechanical properties (such as hardness and wear behavior), when the ratio of the reinforcing element exceeds a critical value, is the most striking feature that distinguishes nano AMCs from conventional particle-reinforced composites. Reasons of this behavior of nano AMCs are particle size, particle shape, inter-surfaces, and agglomerations occurring at grain boundaries [5]. Agglomerations at grain boundaries are shown in Fig. 1. It is also seen that there is a porous structure in A356-2\% CNT in Fig. 1. Significant gaps were formed between $\mathrm{Al}$ matrix grains by adding CNT. No good bonds occur between granules due to increase in these gaps where CNT agglomerations exist and due to lack of interaction between CNTs and $\mathrm{Al}$ matrix. Thus, granules are more easily separated from each other depending on applied load, and wear rate increases (Fig. 3b and c). This case also is supported by literature [9].
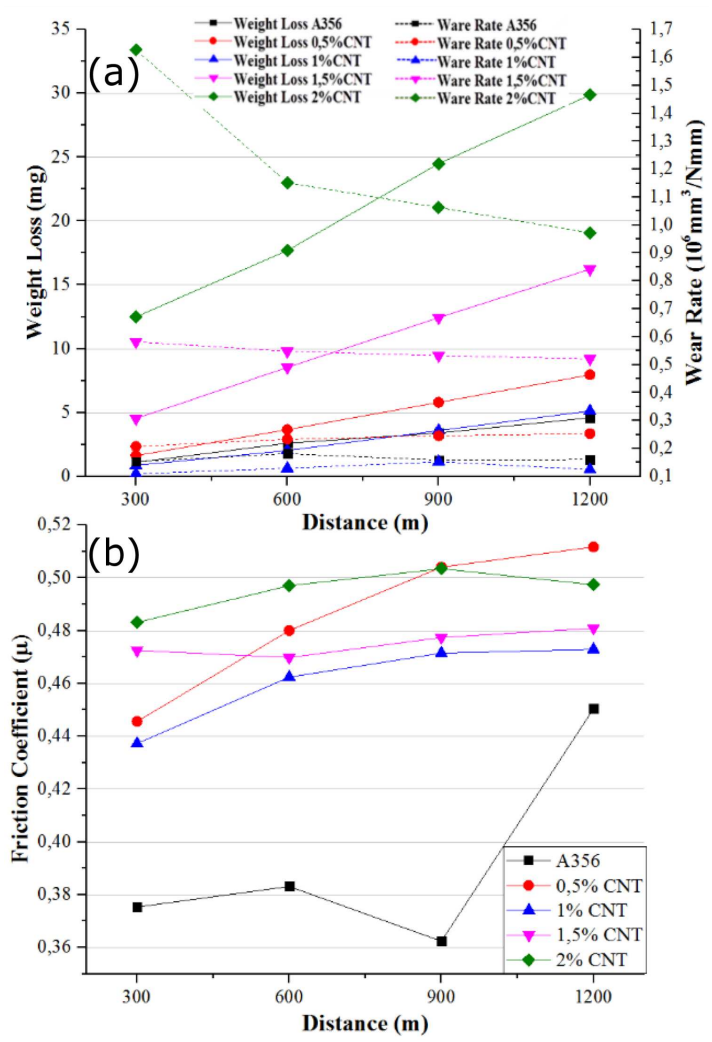

Fig. 3. (a) Wear rate-weight loss, (b) friction coefficient, according to CNT rates and sliding distance under $10 \mathrm{~N}$ load.

Furthermore, Fig. 4 shows the worn surfaces of CNT free A356 matrix material (Fig. 4a) and 2\%CNT containing composite (Fig. 4b). According to Fig. 4a, wear evidences were clearly visible while Fig. $4 \mathrm{~b}$ multi-layered surfaces were formed at A356-2\% CNT composites after wear. It is believed that this is caused by adhesion of particles broken during wear to sample surfaces again and by increase in inter-granular gap amount parallel to CNT content.
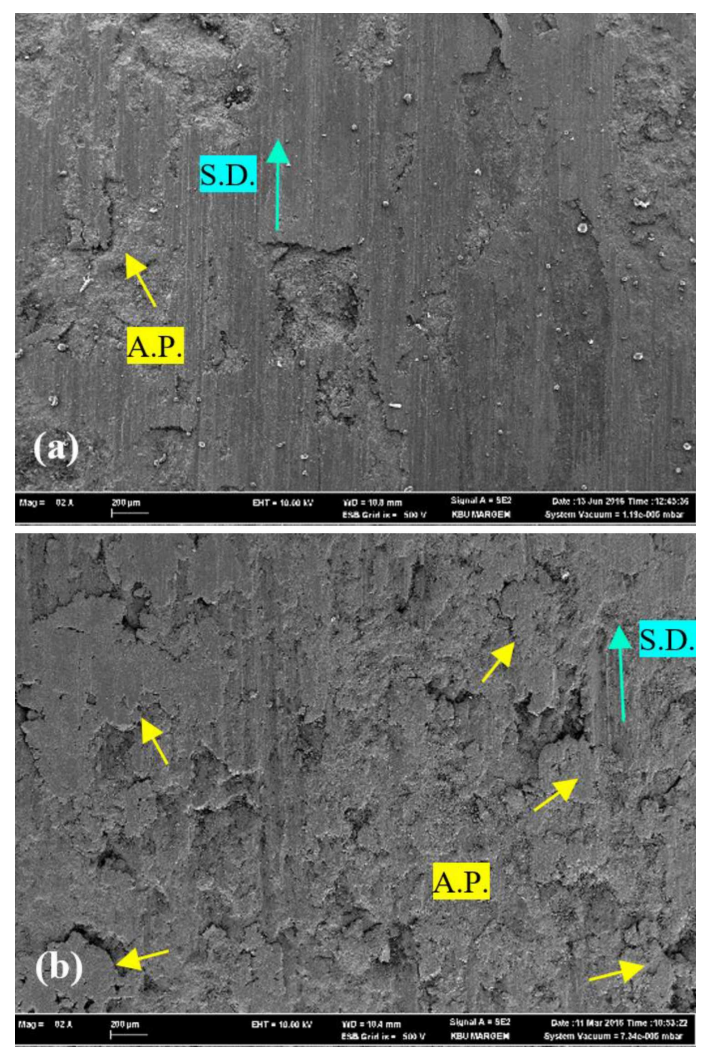

Fig. 4. SEM images of worn surfaces of (a) $0 \%$ CNT, (b) A356-2\%CNT composite (S.D. - sliding direction, A.P. - adherent particles: broken from surface during wear, then adhered to surface again).

\section{Conclusion}

In this study, following results were obtained in hardness, wear, and microstructure properties of A356 matrix composites produced by reinforcing with different ratios of CNT:

- CNT reinforced A356 matrix composites were successfully produced via powder metallurgy method.

- It was observed that the highest hardness value was obtained in 1\% CNT-A356 composite and hardness decreased after this ratio.

- As a result of wear tests, weight loss of composites increased after $1 \%$ rate of CNT.

- Microstructural analysis revealed that CNTs were substantially located as agglomerations between matrix grains, and a more hollow structure, affecting wear resistance adversely, was formed.

\section{Acknowledgments}

The authors thank Scientific Research Project Department of Karabuk University for financial support as part of KBÜ-BAP-14/2-YL-024 numbered project. 


\section{References}

[1] A. Agarwal, S.R. Bakshi, D. Lahiri, Carbon Nanotubes Reinforced Metal Matrix Composites, 1st ed., CRC Press Taylor \& Francis Group, USA 2011.

[2] A. Esawi, K. Morsi, Composites A 38, 646 (2007).

[3] B. Abbasipour, B. Niroumand, S.M.M. Vaghefi, Trans. Nonferr. Met. Soc. China 20, 1561 (2010).

[4] H.H. Kim, J.S.S. Babu, C.G. Kang, Metall. Mater. Trans. A 45, 2636 (2014).

[5] M. Yıldırım, D. Özyürek, M. Gürü, Fuller. Nanotubes Carbon Nanostr. 24, 467 (2016).
[6] C.F. Deng, D.Z. Wang, X.X. Zhang, A.B. Li, Mater. Sci. Eng. A 444, 138 (2007).

[7] A. Baradeswaran, A.E. Perumal, Composites B 54, 146 (2013).

[8] P. Sharma, S. Sharma, D. Khanduja, J. Asian Ceram. Soc. 3, 352 (2015)

[9] D. Özyürek, M. Yıldırım, İ. Çiftçi, Sci. Eng. Compos. Mater. 19, 351 (2012). 